\title{
Annie Ousset-Krief, Les juifs d'Europe orientale aux États-Unis, 1880-1905. Yidn ale brider - Immigration et solidarité
}

Paris, L'Harmattan, coll. « L'aire anglophone », 2009, 316 p.

\section{Régine Azria}

\section{(2) OpenEdition Journals}

Édition électronique

URL : http://journals.openedition.org/assr/24681

DOI : $10.4000 /$ assr.24681

ISSN : $1777-5825$

Éditeur

Éditions de l'EHESS

Édition imprimée

Date de publication : 30 décembre 2012

Pagination : 250

ISSN : 0335-5985

Référence électronique

Régine Azria, «Annie Ousset-Krief, Les juifs d'Europe orientale aux États-Unis, 1880-1905. Yidn ale brider - Immigration et solidarité », Archives de sciences sociales des religions [En ligne], 160 | octobredécembre 2012, mis en ligne le 25 mars 2013, consulté le 21 septembre 2020. URL : http:// journals.openedition.org/assr/24681; DOI : https://doi.org/10.4000/assr.24681

Ce document a été généré automatiquement le 21 septembre 2020.

(C) Archives de sciences sociales des religions 


\section{Annie Ousset-Krief, Les juifs d'Europe orientale aux États-Unis, 1880-1905. Yidn ale brider - Immigration et solidarité}

Paris, L'Harmattan, coll. «L'aire anglophone », 2009, 316 p.

Régine Azria

\section{RÉFÉRENCE}

Annie Ousset-Krief, Les juifs d'Europe orientale aux États-Unis, 1880-1905. Yidn ale brider - Immigration et solidarité, Paris, L'Harmattan, coll. « L'aire anglophone », 2009, $316 \mathrm{p}$. 
1 Dans cet ouvrage, l'auteur, agrégée d'anglais, maître de conférence à l'Université Sorbonne-Nouvelle où elle enseigne la civilisation américaine, pose la question de la pérennité du lien entre les communautés de diaspora. Ce qui l'amène à s'interroger sur la condition juive en diaspora et à se demander si l'on doit parler de peuple juif, lequel suppose une solidarité juive active par-delà les frontières (l'expression yiddish Yidn ale brider qui figure dans le sous-titre signifie "les Juifs sont tous frères") ou se

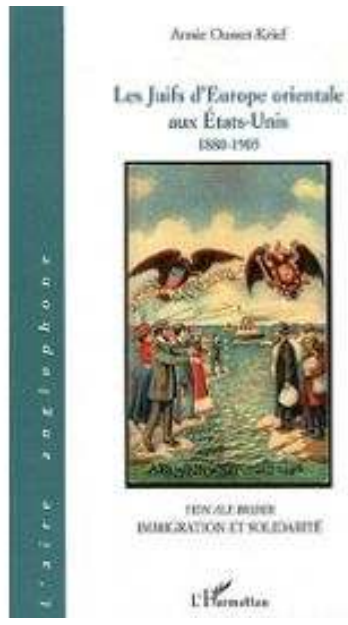
satisfaire de la notion de communauté juive, auquel cas la solidarité se verrait limitée au groupe local. À l'évidence, les deux notions sont complémentaires et la seconde n'est jamais que la manifestation ponctuelle de la première, sous réserve que certaines conditions soient satisfaites. Ainsi, et dans un premier temps, deux conditions étaient nécessaires pour que l'intégration des Juifs d'Europe orientale dans la société nord-américaine (en l'occurrence celle des États-Unis) puisse se faire sans déjudaïsation. La première était l'acceptation par la société hôte du fait communautaire, et la seconde, que la communauté juive soit capable de fonder son unité sur deux valeurs aussi capitales l'une que l'autre: l'une à caractère interne, à savoir le respect de la religion, et la seconde en direction des communautés juives sœurs, à savoir la solidarité.

2 S'agissant des Juifs d'Europe orientale, un des instruments de cette solidarité a été la presse juive. La presse ethnique devait en effet se révéler un outil précieux pour unir et renforcer le sens de l'appartenance, assurer la pérennité du lien communautaire en interne et maintenir le lien avec les coreligionnaires demeurés dans le pays d'origine. Mais cette presse ethnique avait une fonction supplémentaire : stimuler chez les Juifs de l'étranger l'attrait de la société américaine. Cette presse juive, et tout spécialement le Jewish Messenger (fondé en 1854), constitue la source d'information majeure de l'auteur, notamment les articles de ce journal dus à la plume de son fondateur Samuel Myer Isaacs et de ses fils et successeurs. Aussi est-ce à travers le prisme de ce journal communautaire conservateur et de sa ligne éditoriale que sont abordées les questions annoncées. Myer était un Juif séfarade orthodoxe, originaire de Hollande, formé à Londres avant son immigration à New York. Il devait mettre son journal et ses activités militantes au service d'une double cause : œuvrer pour une union des congrégations juives américaines et la solidarité avec les communautés juives opprimées dans le monde, étant bien entendu que l'une et l'autre cause ne devait en aucune manière prévaloir sur la loyauté envers l'Amérique.

Or, dès les années 1870, des dissensions existent au sein des milieux juifs américains quant à la nature du soutien à apporter aux Juifs de Russie : incitation à l'immigration ou aide sur place, via l'éducation, l'économie et le social afin d'y améliorer leur condition, cette seconde option étant celle retenue par les responsables de l'Alliance Israélite Française (fondée en 1860). Ces derniers en effet s'accordent avec leurs correspondants du Board of Delegates of Americain Israelites sur deux points : l'aide sur place dans les domaines de l'éducation et de la reconversion professionnelle vers des 
«métiers utiles», et l'aide à l'installation sur le sol américain, en vue d'une reconversion "agricole». À condition que cette installation se fasse loin des villes à forte concentration de population juive (ce projet sera un échec). Car il importe de ne pas alimenter les préjugés et les stéréotypes qui identifient les Juifs à l'argent et au commerce. Faut-il s'en réjouir ou le déplorer? Toujours est-il que l'Europe ne détient pas le monopole des préjugés et des stéréotypes antisémites. Pourtant, l'aggravation soudaine de la situation des Juifs en Russie bouleverse la donne. L'arrivée sur le sol de l'Amérique entre 1881 et 1914 de plus de deux millions de personnes met cette fraternité revendiquée à l'épreuve des faits.

4 Se pose alors une autre question: faut-il inciter les Juifs à émigrer, autrement dit persuader les pays hôtes potentiels (France, Hollande, Grande-Bretagne, États-Unis) d'accepter l'arrivée massive d'immigrants alors même que les Juifs de ces pays sont partagés entre solidarité et crainte face à la menace que représente ce contre-modèle ? Car il ne fait pas de doute que le contraste est frappant entre le judaïsme occidental confessionnalisé et libéral des dirigeants juifs des «nations éclairées », et le judaïsme, orthodoxe et totalisant, obscurantiste et grossier des émigrants russo-polonais.

5 Solidarité certes, néanmoins l'immigration doit être limitée en nombre, sélective en qualité. Sinon, comment concilier les grands principes et les craintes que soulève leur mise en œuvre ? D'abord en pratiquant une sélection sévère à l'arrivée, en refoulant les inaptes au travail et les cas les plus lourds, car la misère, la pauvreté, l'oisiveté des immigrés sont considérées comme des tares dont on ne veut pas chez soi. Ensuite en réhabilitant le quartier du Lower East Side de New York, où les nouveaux venus auxquels s'intéresse le Jewish Messenger sont concentrés : en réformant l'habitat et en proposant une éducation appropriée au monde moderne, incluant les filles, comportant un enseignement des matières profanes et prioritairement tourné vers l'apprentissage professionnel; en remplaçant le yiddish, la langue de l'Ancien Monde, mais aussi et surtout des syndicats et des socialistes athées et honnis, par l'anglais, la langue qui incarne l'Amérique et qui véhicule ses valeurs.

6 Par la voix de leur organe, le Jewish Messenger, et de leur porte-parole Myer Isaacs, les conservateurs juifs américains expriment leur vive opposition tant à l'orthodoxie des Juifs russes du downtown qu'aux ouvriers juifs immigrés syndicalisés, lecteurs du journal yiddish socialiste Forwarts (En avant!). Ils s'enflamment aussi contre les anarchistes juifs. Quant au sionisme émergeant auquel adhèrent principalement les immigrés, il ne manque pas d'être perçu par eux comme une autre forme de menace, une remise en question de leur loyauté envers leur seul pays, l'Amérique. Peuple ou communauté?

7 À la fin du xix ${ }^{e}$ siècle, les Juifs immigrés de Russie dépassent en nombre les Juifs américains. Ils ont mis en place leurs propres institutions d'entraide, les landmanschaftn, et sont capables de se prendre en charge. Ils peuvent désormais dénoncer le paternalisme et l'arrogance de leurs "frères " américains envers leurs « frères » immigrés moins bien nantis.

8 Comment, s'interroge l'auteur, expliquer la force de ce lien qui, par-delà les frontières, les différences sociales et les oppositions idéologiques, rapproche des êtres et des groupes aussi divers, autrement qu'en invoquant cette "mystérieuse unité raciale», une expression citée par l'auteur mais à laquelle elle préfère la notion de " peuple », les deux termes renvoyant, ajoute-t-elle, à une même réalité : le sentiment d'appartenance communautaire appelant à la solidarité extraterritoriale. 